\title{
The Secular Tendency of the Age at Menarche in a Representative Sample of Mexican Girls from an Urban Zone in Central Mexico
}

\author{
María-Raquel Huerta-Franco ${ }^{*}{ }^{*}$, Francisco-Miguel Vargas-Luna ${ }^{2}$, \\ Elba del Rosario Huerta-Franco3, Aminta Jimenez-Velazquez ${ }^{4}$, Marco Balleza², \\ Isabel Delgadillo-Holford ${ }^{2}$ \\ ${ }^{1}$ Applied Sciences to Work Department, Division of Health Sciences, Campus Leon, University of Guanajuato, \\ León, Mexico \\ ${ }^{2}$ Engineering Physics Department, Division of Science and Engineering, Campus Leon, University of Guanajuato, \\ León, Mexico \\ ${ }^{3}$ Dentistry Clinic of the University of Guadalajara, Guadalajara, Mexico \\ ${ }^{4}$ Institute for Social Security and Services for the State Workers from Leon, Guanajuato, Mexico \\ Email: "huertafranco@hotmail.com
}

Received 29 September 2015; accepted 9 November 2015; published 12 November 2015

Copyright (C) 2015 by authors and Scientific Research Publishing Inc.

This work is licensed under the Creative Commons Attribution International License (CC BY).

http://creativecommons.org/licenses/by/4.0/

(c) (i) Open Access

\section{Abstract}

Objective: To investigate the age at menarche, pubarche and telarche in a representative sample of residents of an urban zone of Leon, Guanajuato, Central Mexico and to evaluate the secular change of the age at menarche between 1985 and 2000. Methods: Using status quo and retrospective methods, menarcheal, pubarcheal and telarcheal status of girls 8 - 17 years of age $(n=1093)$ were determined. Multiple regression analysis and logistic regression were used to determine factors that were related to or predictive of age at menarche. Results: Median ages for menarche, pubarche and telarche in our studied sample were: $11.9 \pm 0.04 ; 11.13 \pm 1.25$ and $10.84 \pm 1.34$ years, respectively. A direct correlation was found between the age at menarche of adolescents and that of their mothers $(p<0.001)$ and sisters $(p<0.001)$, in addition to the girls' waist circumference $(p$ $=0.001)$, but an indirect correlation was found with the girls' hip circumference $(p=0.004)$. We demonstrated a clear secular tendency towards an earlier onset of menarche by comparing our results (11.9 \pm 0.04$)$ with data from $1985(12.8 \pm 1.3)$ for adolescents from the same city. Conclusion: We demonstrated a clear reduction in age at menarche of approximately 0.75 year/decade, higher than Tanner's finding in 1962, but similar than that of Malina et al. in 2004.

\footnotetext{
${ }^{*}$ Corresponding author.
} 


\section{Keywords}

\section{Age at Menarche, Adolescent Girls, Secular Tendency}

\section{Introduction}

Recently, there have been many reports demonstrating a secular tendency toward an early onset of puberty and menarche [1]-[4]. In 1962, Tanner reported that the age at menarche diminished four months per decade [5]. British and American trials also clearly show the same tendency, by comparing the mean age at menarche reported in 1840 at 16.5 years with the mean age for the last decade, 13 years [6]. However, considering data from the last 50 years, such tendencies no longer appear significant in other European countries (Iceland, Poland, Italy and Sweden) [6]. Data from third world countries around the world (India, Dominican Republic, Mali and Cameroon) [7]-[11], showed the same tendency toward a younger onset of puberty as was found in the United States and England. After considering these international findings, we decided to investigate the age at menarche, pubarche and telarche in a representative sample of Mexican girls and to analyze these data in conjunction with anthropometrical variables, age at menarche of mothers and sisters, regular exercise, emotional stress, and other factors to ascertain if any of them are predictors of the age of the onset of puberty.

\section{Methods}

\subsection{Sampling}

This study was conducted in local elementary schools and therefore was approved by the Secretary of Public Education of Leon, Guanajuato, Mexico. The protocol was also approved by the Committee of Bioethics from our institution, and was conducted according to the Declaration of Helsinki. Once the objectives of the study were explained to the authorities of each school selected for the study, meetings were held with the girls and then with their parents to explain the objectives of the study and request their consent to participate in it. The girls should provide a signed consent form by their parents or legal guardians who authorized the participation of their daughters in the study. In the study were included just those girls who voluntarily agreed to participate in the study and whose parents gave the written consent for their daughters to be evaluated. We performed a random sampling of elementary schools from within the urban zone of the city of Leon Guanajuato, Mexico, and selected 19 schools. We took subjects from high, middle, and low socio-economic backgrounds.

\subsection{Anthropometrical Evaluation}

Body weight was measured to an accuracy of $0.1 \mathrm{~kg}$ (weight), and height was measured to the nearest millimeter using a wall-mounted stadiometer. Body mass index was then calculated (BMI weight $[\mathrm{kg}] / \mathrm{height}^{2} \cdot\left[\mathrm{m}^{2}\right]$ ). Measurements of the waist circumference (which was measured during the mid-inspiratory phase, midway between the xyphoid and the umbilicus); hip measurements were taken at the maximum circumference of the hip area; and abdomen (which was measured at the mid-inspiratory phase, at the level of the umbilical scare). Measurements taken using non-flexible measuring tapes with a tension were also taken in order to determine waist/ hip and abdomen/hip indexes. We then used a Lange brand caliper (Cambridge, Maryland, USA), to measure skin-folds (tricipital, sub-scapular and supra-iliac) in millimeters. These values were used to determine tricipital/ sub-scapular and sub-scapular/supra-iliac indexes of each girl. In order to avoid intra-person variability, all the anthropometrical measures were made by one researcher (MRHF).

\subsection{General Information}

Using the date of the interview and the date of birthday, we calculated the volunteers' age in years; we also asked questions about the number of years in school and the socio-economic level, which was determined by the place of residence, the girl's parent's occupation and their schooling levels, and family income. Our clinical evaluation included the following four sections:

1) Physical Exercise and Life-Style: We asked questions related with the type, time in months, days/week, and 
number of minutes practicing physical activity. We also asked questions concerning the use of tobacco, alcohol beverages, or drugs that have effects at the Nervous System level.

2) Medical History: We assessed mental or physical impairment that could possibly affect responses to our questionnaire. Additionally, we inquired about chronic or endocrine disease that could limit growth and/or sexual development.

3) Sexual Development: All the girls were evaluated from 8 to $12 \mathrm{AM}$, and during the interviews, girls were asked about the age at which they experienced their first menstruation. Based on the assumption that women reporting age at menarche from recall tend to report the age at the last birthday preceding menarche, 0.5 years was added to the reported age [8] [10] to obtain an adjusted age at menarche. The same procedure of recall was used to asked the adolescent girls' mothers and sisters age at menarche. The ages at telarche and pubarche were determined asking about the age at which they experienced their breast development and pubic hair growth using drawings showing the stages of breast development and pubic hair growth of Tanner [5].

4) Psychological Stress: To assess stress, we gave subjects the Cohen Global Scale for Stress Perception [12], which included 26 items. This questionnaire was previously validated in a sample of 20 girls, by asking them whether or not they have recently experienced stressful events, and using their feedback to adjust the questions. In order to understand how the girls perceived stress, we used the Liker scale, in which subjects rated their responses in one of the following ways: totally agree, agree, indifferent, disagree and totally disagree. We rated these categories from 1 to 5 points, with lower point values corresponding to less stressful experiences, and higher values corresponding to more stressful experiences. We assessed subjects' history of acute and chronic stress according to the $3^{\text {rd }}$ revised edition of the Diagnostic Statistical Manual (DSM-III-R) [13], which classifies acute and chronic stress in 6 groups, based on past and present situation in the girls' lives. Classifications ranged from a score of 0 , corresponding to an absence of stress to a score of 5 , representing catastrophic stress.

\subsection{Statistical Analysis}

The ages at menarche, telarche and pubarche were calculated by a status quo procedure. Within each age group, we found the proportion of girls who had already presented each of the above events. We then plotted these percentages as a function of age, which can be seen in Figures 1-3. Using a logistic regression, we interpolated the median ages at menarche, telarche and pubarche, based on the point in the regression line at which $50 \%$ of the girls and adolescents had presented the event. Because of this method, the calculated medians for the ages at menarche, pubarche and telarche were not simply based on estimations of the mean values obtained from the girls and teenagers who participated in our study. The logistic regression was calculated using a maximum probability procedure with a logistic model. The "Equation (1)” used was:

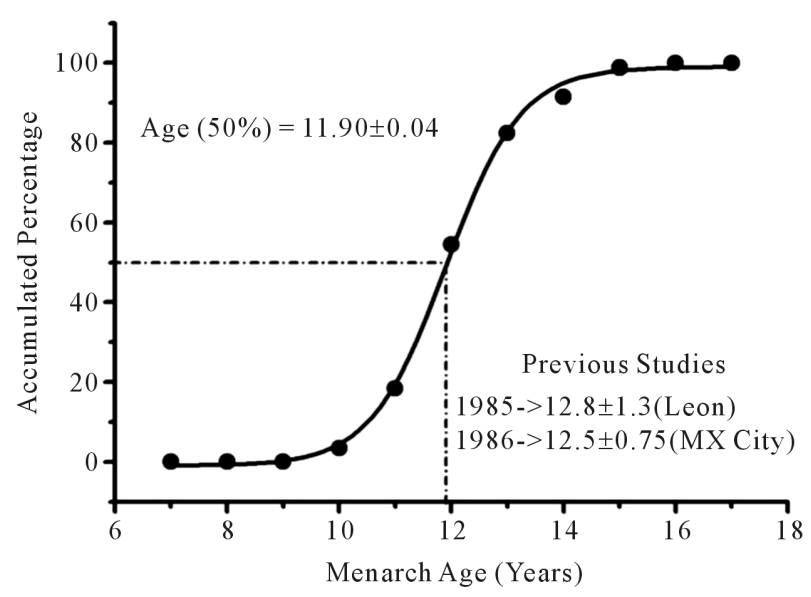

Figure 1. Demonstrate a clear reduction in the age at menarche of girls and adolescents from Leon, Guanajuato Mexico (Center of Mexico), when we compare our results (11.9 \pm 0.04 ) for 971 girls and adolescents with that reported in 1985 $(12.8 \pm 1.3)$ for 1500 subjects evaluated in the same city using in both studies the status quo procedure [15]. 


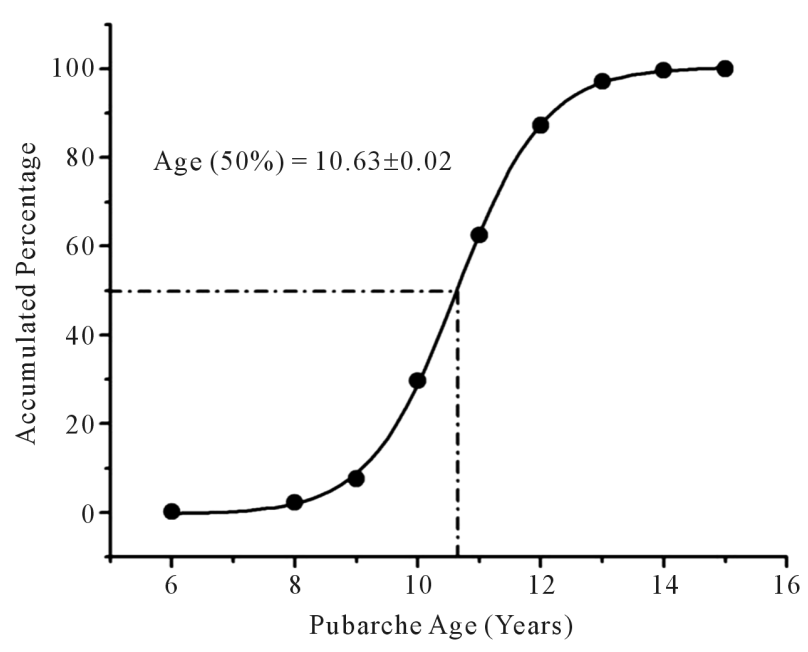

Figure 2. Shows the median age at pubarche (10.63 \pm 0.02$)$, determined by a status quo procedure (for more explanation see methodology section).

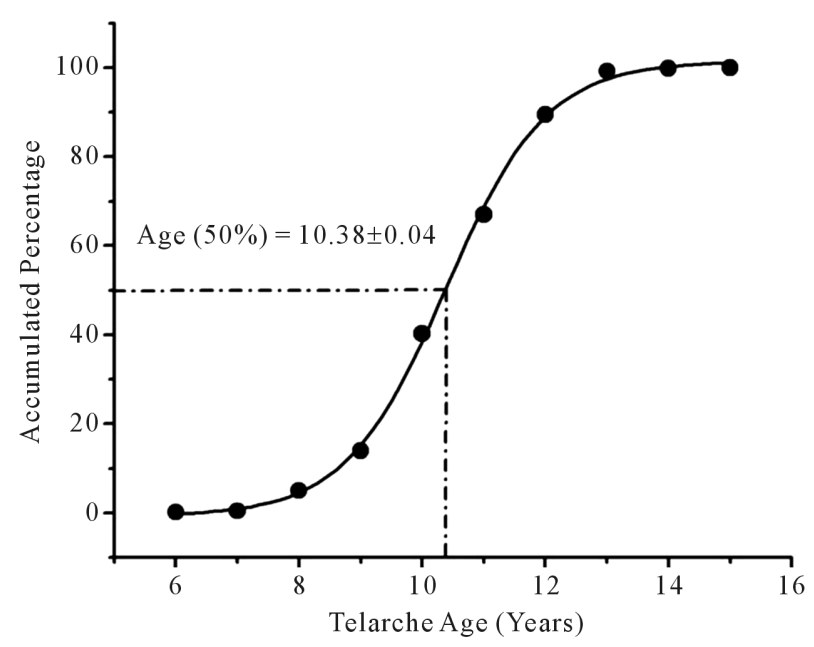

Figure 3. Shows the median age at telarche $(10.38 \pm 0.04)$, determined by a status quo procedure (for more explanation see methodology section).

$$
p=\frac{\mathrm{e}^{b(x-a)}}{1+\mathrm{e}^{b(x-a)}}
$$

where $p$ is the probability for a given age at menarche, pubarche or telarche, $x$ is age, $a$ is the median age at menarche, pubarche or telarche (based on the equation) and $b$ is related to the inflection of those curves. In this study, we considered important factors known to be involved with the age of the onset of puberty and incorporated them into our statistical analyses. Specifically, we considered the ages at menarche of mothers and sisters, the anthropometrical variables (weight, height, waist, hip and abdomen circumferences), BMI, skin-folds (tricipital, sub-scapular and supra-iliac), and socio-economic variables as regressors, with the age at menarche of the subject as the dependent variable, using a forward step-wise multiple regression analysis. In order to understand the relationship of other possible predictors to the actual age of the onset of puberty, we also used a logistic regression analysis using lifestyle variables (physical exercise, tobacco, alcohol beverages, or drugs that have effects at the Nervous System level) and the total scores of the degree of stress as regressors and the age at menarche as the dependent variable. All analyses were performed with STATISTICA, Stat-Soft, Inc, Tulsa OK, and the threshold for significance was standardized at $p=0.05$. 


\section{Results}

\subsection{Study Sample General Characteristics}

General data from the studied sample group is shown in Table 1. The mean age and years of schooling of the subjects who participated in our trial were: $12.35 \pm 2.13$ years $(\mathrm{X} \pm \mathrm{SD})$ and $6.51 \pm 1.95$ years, respectively. Sixty-seven girls (6.9\%) came from a low socio-economical background, 467 (48.1\%) came from the middle class and 430 (44.3\%) were from a high socio-economical background. Mean age of the parents were $40 \pm 7.2$ years for the father and $37.7 \pm 6.3$ years for the mother. The number of children per family was $4.6 \pm 2.3$. Ninety six percent of all girls had experienced some infectious disease (mostly diarrhea and amygdalitis), but these did not affect the nutritional state or sexual development of the girls.

\subsection{Ages at Menarche, Pubarche and Telarche}

Median ages for menarche, pubarche and telarche in our studied sample determined by a status quo procedure were: $11.9 \pm 0.04 ; 11.13 \pm 1.25$ and $10.84 \pm 1.34$ years, respectively (Figures 1 -3). In Table 2 , we show the distribution of subjects grouped by age that had experienced the onset of menarche.

\subsection{Physical Exercise and Lifestyle}

Seven hundred and twenty-one girls (74.2\%) practiced regular exercise. The other $22.4 \%$ of the girls did not practice any exercise at all. Eighty-five girls (8.7\%) occasionally drank alcohol, 69 (7.1\%) had a history of smoking; and three (0.3\%) had taken illegal drugs at some point of their life.

\subsection{Factors Associated with the Age at Menarche}

By using a simple regression analysis, we observed that the age at menarche of mothers and sisters was directly related to the age at menarche of the subjects. However it appears that there is a stronger correlation between the age at menarche in sisters than there is between mothers and their daughters, with values of $\mathrm{r}=0.3, p<0.001$ and $\mathrm{r}=0.5, p<0.001$, respectively. Using a forward step-wise multiple regression analysis, we also observed that the following variables are correlated to the age at menarche of the subjects: the age at menarche of the sister(s) $(p<0.001)$, the subjects' years of schooling level $(p<0.001)$, the waist circumference $(p=0.001)$, the abdomen circumference $(p=0.03)$, and the hip circumference $(p=0.004)$ (Table 3$)$.

Table 1. Shows the general characteristics of the sample group.

\begin{tabular}{|c|c|c|}
\hline Variable & No. & Mean \pm SD \\
\hline Age $^{*}$ & 971 & $12.35 \pm 2.13$ \\
\hline Years of Schooling* & 757 & $6.51 \pm 1.95$ \\
\hline Weight (Kg) & 966 & $43.44 \pm 12.39$ \\
\hline Height (Cm) & 967 & $148.23 \pm 11.06$ \\
\hline $\mathrm{BMI}\left(\mathrm{Kg} / \mathrm{m}^{2}\right)$ & 965 & $19.42 \pm 3.85$ \\
\hline Waist/Hip Ratio & 965 & $0.78 \pm 0.05$ \\
\hline Abdomen/Hip Index & 913 & $0.83 \pm 0.05$ \\
\hline S/T index ${ }^{\dagger}$ & 961 & $0.74 \pm 0.24$ \\
\hline S/SI Index ${ }^{\ddagger}$ & 956 & $1.07 \pm 0.27$ \\
\hline Sub Scapular Skinfold & 962 & $11.57 \pm 4.58$ \\
\hline Socio-Economic Status & 964 & $2.37 \pm 0.61$ \\
\hline
\end{tabular}

$\mathrm{SD}=$ Standard Deviation; ${ }^{*}$ Data in years; ${ }^{\dagger} \mathrm{S} / \mathrm{T}$ index = sub-scapular/tricipital index; ${ }^{\ddagger} \mathrm{S} / \mathrm{SI}$ Index $=$ sub-scapular/supra-iliac index. 
Table 2. Number of girls by age group who had already experienced the onset of menarche.

\begin{tabular}{cccccccc}
\hline $\begin{array}{c}\text { Age Groups } \\
\text { (years) }\end{array}$ & 8 & 9 & 10 & 11 & 12 & 13 & 14 \\
\cline { 2 - 7 } 7 & 0 & 0 & 0 & 0 & 0 & 0 & 0 \\
8 & 0 & 0 & 0 & 0 & 0 & 0 & 0 \\
9 & 0 & 0 & 0 & 0 & 0 & 0 & 0 \\
10 & 1 & 1 & 1 & 0 & 0 & 0 & 0 \\
11 & 0 & 3 & 8 & 10 & 0 & 0 & 0 \\
12 & 0 & 2 & 17 & 62 & 34 & 0 & 0 \\
13 & 0 & 3 & 11 & 37 & 43 & 9 & 0 \\
14 & 1 & 3 & 8 & 38 & 48 & 44 & 10 \\
15 & 0 & 1 & 5 & 19 & 34 & 20 & 3 \\
16 & 0 & 0 & 0 & 3 & 6 & 4 & 3 \\
17 & 0 & 0 & 0 & 0 & 1 & 0 & 0 \\
All groups & 2 & 13 & 50 & 169 & 166 & 77 & 16 \\
\hline
\end{tabular}

The number of girls who had menarche appears in the columns, and grouped according to age groups, demonstrating that the higher number of girls whose presented menarche was among those who had 11 and 12 years old.

Table 3. Results of the step-wise multiple regression analysis.

\begin{tabular}{cccc}
\hline \multirow{2}{*}{ Regressors } & \multicolumn{3}{c}{ Dependent Variable: Age at Menarche } \\
\cline { 2 - 4 } & $\beta$ & $\mathrm{t}$ & $p$ \\
\hline Sister's Age at Menarche & 0.39 & 4.9 & $<0.001$ \\
Years of Schooling & 0.36 & 4.2 & $<0.001$ \\
Hip Circumference & -0.44 & -3.2 & 0.001 \\
Waist Circumference & 0.63 & 2.9 & 0.004 \\
Abdomen Circumference & -0.40 & -2.0 & 0.03 \\
\hline
\end{tabular}

Show that the age at menarche of sisters', and the volunteers' waist circumference had a positive correlation with their age at menarche. However, their hip and abdomen circumferences showed a negative relationship.

\subsection{Results from the Logistic Regression Analysis}

Predictors found to be correlated with the onset of menarche of subjects were: the history of smoking $(\mathrm{B} 0=1.02$, $\mathrm{t}=2.18, p=0.02)$, alcohol consumption ( $\mathrm{B} 0=1.28, \mathrm{t}=3.3, p<0.001)$, and variations of individual weight of each subject over the preceding three months ( $\mathrm{B} 0=0.38, \mathrm{t}=2.44, p=0.01$ ). Additionally, high levels of stress in the subjects and a small waist/hip index were also predictors of the age at menarche. The practice of regular exercise and the use of illegal drugs (different than tobacco and alcohol) did not have any significant relationship with the age at menarche.

\section{Discussion}

A secular change in the development of children is one in which the developmental pattern changes progressively as a function of time in a given population. Such changes generally include the increase or decrease in age 
when at a given height, weight, or when a particular characteristic of maturity occurs. Additional examples include a change in the velocity of growth over a given increment of time, early maturation, or early cessation of linear growth.

The results of this study show a clear secular tendency toward an early onset of menarche in a representative sample of girls and adolescents from the urban area of the city of Leon, Guanajuato in central Mexico. In our study, we found that the median age at menarche was $11.9 \pm 0.04$ years, which is significantly earlier than the age reported by Malina et al., in residents of a rural Zapoteco-speaking community in Oaxaca, Mexico [14]. In his study, Malina et al. demonstrated that the median ages at menarche of adolescents from Oaxaca were $14.8 \pm$ 1.2 years in 1978 and $13.0 \pm 1.0$ years in 2000 . These investigators also demonstrate that age at menarche has declined by 1.8 years over about 23 years, 0.78 years/decade $(95 \% \mathrm{CI}=0.65-0.91$ year/decade). Our results demonstrate a clear reduction in the age at menarche of girls and adolescents from Leon, Guanajuato Mexico, when we compare our results $(11.9 \pm 0.04)$ with that reported in $1985(12.8 \pm 1.3)$ with a sample of 1500 girls and adolescents evaluated in the same city [15]. Looking at our results in conjunction with that previously reported in Leon, Guanajuato, Mexico, we observe a reduction of about 0.75 year/decade, which is consistent with that of Malina et al. [14], but higher than that reported by Tanner in 1962 [5]. Conversely, our findings are distinctly different than those reported in developed countries, such as the United States, England and Japan regarding the age at menarche. Specifically, trials performed in American [16] and British [17] girls and adolescents show that the age at menarche has changed very little in the past 30 years (approximately 0.4 years), which is not a significant difference. Based on these findings, we no longer consider that there is a secular tendency in these countries. Nevertheless, countries such as India [7], Iran, Hungary, Spain, the Dominican Republic and Guatemala still report a secular tendency towards an early age at menarche [18].

We suggest several reasons that may account for the differences seen between these two groups of countries. First, in the studies conducted in developing countries around the world, the data collection regarding the age at menarche among the studies was not standardized (no representative sample sizes, different methods for statistical analysis and reporting (median and mean values), prospective and retrospective methods of data collection and different age groups of the subjects studied) [18]-[20]. Also, the observed differences may be due to genetic factors, specific to the area in which the study was conducted, as evidenced by the high proportion of mothers and sisters that had highly correlated age of presentation of menarche, as we demonstrated in this study. Local customs can also affect nutrition of a population of individuals, which can subsequently affect anthropometrical characteristics and body composition [19]-[26]. Additionally, socioeconomic factors and environmental pollutants may contribute to the secular tendency in the age at menarche seen in these countries [27]. In this study, our findings demonstrated a secular tendency of the age at menarche, as did Malina and other investigators in developing countries [28]. Among the factors that we analyzed, genetic factors were most commonly related to an early age at menarche, exemplified by the close correlation of the subjects' age at menarche and that of their mothers and sisters. In this study, the results of logistic analysis, demonstrated that predictors found to be associated with the onset of menarche of subjects were: the history of smoking, alcohol consumption, and the variations of weight over the preceding three months. Also, high levels of stress and a small waist/hip index were predictors of the age at menarche. The practice of physical exercise and the use of illegal drugs (different than tobacco and alcohol) did not have any significant relationship with the age at menarche; the practice of physical exercise, probably because it is not of sufficient intensity to produce delayed of sexual development, and the use of various drugs different that alcohol or tobacco, likely because the number of girls who use them is not very high (0.3\%) [29].

Finally, we suggest the following hypothesis to explain the secular trend in the early onset at age at menarche for girls of Leon, Guanajuato, Mexico: 1) Worldwide, Mexico occupies one of the first places in child obesity [30] [31]; because in the last decades the lifestyle of children is changing to a more sedentary lifestyle, resulting in an increase in the percentage of body fat [22], in the body fat the androgens are aromatized to estrogen, increasing the estrogens serum levels, which produced early sexual maturity [32]; 2) in modern Mexican families, the mother's family is involved in the workforce and there is not time to prepare healthy food, so the intake of fast foods with high content in calories is very common, which in turn leads to the children gain weight and increases in body fat necessary to begin the sexual maturation [30] [31]; 3) probably the intake of meat contaminated with anabolics, have systemic effects in children producing clinical manifestation such as acne, increased body fat, aggressive behavior, and advance in sexual maturity, among others; 4) the exposition to the environmental endocrine disruptors have effects on children with idiopathic precocious puberty [33]. All mentioned 
hypothesis should be tested and study them carefully to ascertain the causes of the reduction in the age of onset of menarche and sexual maturation of Mexican girls.

\section{Conclusion}

In conclusion, in this study we proved that in a population of Mexican girls, there is a clear secular tendency toward a lower age at menarche. This finding has important implications for policy and health officials because of the social implications of this age reduction. Specifically, when governments and institutions aim educational efforts at pre-pubertal girls, they must clearly establish the age at which they initiate the programs. Based on the results of this study, which demonstrate a lower age at menarche than in previous generations, health organizations and agencies must acknowledge that girls may not have finished their elementary education before the onset of menarche. For this reason, it is important that institutions make information regarding sexual and reproductive health accessible to a younger audience. Finally, it is important that researchers continue to monitor the secular tendency in a representative Mexican population in order to assess whether the age at menarche continues to decline, or to identify the time when it reaches a steady state, as it has in the United States and England.

\section{Acknowledgements}

This work was conducted with the support from the University of Guanajuato and the University of Guadalajara. They supported with staff that collaborated on this study. The authors thank all the girls and their parents who kindly consented to their daughters' evaluation, and also to The Secretary of Education of Guanajuato who gave us permission to conduct an investigation in elementary schools.

\section{References}

[1] Susanne, C., Bodzar, E., Bielicki, T., Hauspie, R., Hulanicka, B., Lepage, Y., Rebato, E. and Vercauteren, M. (2001) Changements Séculaires de la Croissance et du Développement en Europe. Antropo, 71-90. www.didac.ehu.es/antropo

[2] Palmert, M.R. and Boepple, P.A. (2001) Variation in the Timing of Puberty: Clinical Spectrum and Genetic Investigation. Journal of Clinical Endocrinology \& Metabolism, 86, 2364-2368.

http://press.endocrine.org/doi/full/10.1210/jcem.86.6.7603 http://dx.doi.org/10.1210/jcem.86.6.7603

[3] Bodzar, E.B. (2000) Studies on Sexual Maturation of Hungarian Children. Act Biol Sze, 44, 155-165. http://www2.sci.u-szeged.hu/ABS

[4] Papadimitriou, A., Chiotis, D., Tsiftis, G., Hatzisimeon, M.M., Krikos, X., Tzonou, A. and Dacou-Vouttakis, C. (2002) Secular Growth Changes in the Hellenic Population in the Twentieth Century. Hormones, 1, 245-250. http://dx.doi.org/10.14310/horm.2002.1174

[5] Tanner, J.M. and O’keeffe, B. (1962) Age at Menarche in Nigerian School Girls, with a Note on Their Heights and Weights from Age 12 to 19. Human Biology, 34, 187-196. http://www.jstor.org/stable/41448557,PMID:13984888

[6] Rees, M. (1995) The Age of Menarche. ORGYN, 4, 2-4.

[7] Bagga, A. and Kulkarni, S. (2000) Age at Menarche and Secular Trend in Maharashtrian (Indian) Girls. Act Biol Sze, 44, 53-57. http://ttkde4.sci.u-szeged.hu/ABS/Acta\%20HP/44-53.pdf

[8] Padez, C. (2003) Social Background and Age at Menarche in Portuguese University Students: A Note on the Secular Changes in Portugal. American Journal of Human Biology, 15, 415-427.

[9] Pawloski, L.R. (2002) Growth and Development of Adolescent Girls from the Ségou of Mali (West Africa). American Journal of Physical Anthropology, 117, 364-372. http://dx.doi.org/10.1002/ajpa.10037

[10] Padez, C. (2003) Age at Menarche of Schoolgirls in Maputo, Mozambique. Annals of Human Biology, 30, 487-495. http://dx.doi.org/10.1080/0301446031000111401

[11] Bosch, A.M., Willekens, F.J., Baqui, A.H., Van Ginneken, J.K. and Hutter, I. (2008) Association between Age at Menarche and Early-Life Nutritional Status in Rural Bangladesh. Journal of Biosocial Science, 40, 223-237. http://dx.doi.org/10.1017/S0021932007002490

[12] Cohen, S., Kamarck, T. and Mermelstein, R.A. (1983) Global Measure of Perceived Stress. Journal of Health and Social Behavior, 24, 385-396. http://dx.doi.org/10.2307/2136404

[13] American Psychiatric Association (1994) Diagnostic and Statistical Manual for Mental Disorders. Third Edition, Revised, APA, Washington DC. 
[14] Malina, R.M., Peña Reyes, M.E., Tan, S.K. and Little, B.B. (2004) Secular Change in Age at Menarche in Rural Oaxaca, Southern Mexico: 1968-2000. Annals of Human Biology, 31, 634-646. http://dx.doi.org/10.1080/03014460400018085

[15] Jacobo, M. and Malacara, J. (1985) Correlation of Menarche with Age and Various Somatometric Indexes. Boletín Médico del Hospital Infantil de México, 42, 37-41.

[16] Chumlea, W.C., Schubert, C.M., Roche, A.F., Kulin, H.E., Lee, P.A., Himes, J.H. and Sun, S.S. (2003) Age at Menarche and Racial Comparisons in US Girls. Pediatrics, 111, 110-113. http://dx.doi.org/10.1542/peds.111.1.110

[17] Whincup, P.H., Gilg, J.A., Odoki, K., Taylor, S.J.C. and Cook, D.J. (2001) Age of Menarche in Contemporary British Teenagers: Survey of Girls Born between 1982 and 1986. BMJ, 322, 1095-1096. http://dx.doi.org/10.1136/bmj.322.7294.1095

[18] Thomas, F., Renaud, F., Benefice, E., De Meeüs, T. and Guegan, J.F. (2001) Internacional Variability at Menarche and Menopause: Patterns and Main Determinats. Human Biology, 73, 271-290. http://dx.doi.org/10.1353/hub.2001.0029

[19] Torres-Mejia, G., Lea, A., Cupul-Uicab, B.A., Galal, O., Salazar-Martínez, E. and Lazcano-Ponce, C. (2005) Comparative Study of Correlates of Early Age at Menarche among Mexican and Egyptian Adolescents. American Journal of Human Biology, 17, 654-658. http://dx.doi.org/10.1002/ajhb.20420

[20] Bagga, A. and Kulkarni, S. (2000) Age at Menarche and Secular Trend in Maharashtrian (Indian) Girls. Acta Biologica Szegediensis, 44, 53-57. http://ttkde4.sci.u-szeged.hu/ABS/Acta\%20HP/44-53.pdf

[21] McDaniel, M., O’Neill, C., Metz, R.P., Tarbutton, E., Stacewicz-Sapuntzakis, M., Heimendinger, J., Wolfe, P., Thompson, H. and Schedin, P. (2007) Whole-Food Sources of Vitamin A More Effectively Inhibit Female Rat Sexual Maturation, Mammary Gland Development, and Mammary Carcinogenesis than Retinyl Palmitate. Journal of Nutrition, 137, 1415-1422.

[22] Kaplowitz, P.B., Slora, E.J., Wasserman, R.C., Pedlow, S.E. and Herman-Giddens, M.E. (2001) Earlier Onset of Puberty in Girls: Relation to Increased Body Mass Index and Race. Pediatrics, 108, 347-353.

[23] Koo, M.M., Rohan, T.E., Jain, M., McLaughlin, J.R. and Corey, P.N. (2002) A Cohort Study of Dietary Fibre Intake and Menarche. Public Health Nutrition, 5, 353-360. http://dx.doi.org/10.1079/PHN2002261

[24] Plant, T.M. (2001) Neurobiological Bases Underlying the Control of the Onset of Puberty in the Rhesus Monkey: A Representative Higher Primate. Frontiers in Neuroendocrinology, 22, 107-139. http://dx.doi.org/10.1006/frne.2001.0211

[25] Barsom, S.H., Dillaway, H.E., Koch, P.B., Ostrowski, M.L. and Mansfield, P.K. (2008) The Menstrual Cycle and Adolescent Health. Annals of the New York Academy of Sciences, 1135, 52-57. http://dx.doi.org/10.1196/annals.1429.001

[26] Jovanović, H., Prebeg, Z., Stanić, I. and Vuletić, G. (2003) Impact of War on Growth Patterns in School Children in Croatia. Collegium Antropologicum, 27, 573-579.

[27] Selevan, S., Rice, D.C., Hogan, K.A., Euling, S.Y., Pfahles-Hutchens, A. and Bethel, J. (2003) Blood Lead Concentration and Delayed Puberty in Girls. The New England Journal of Medicine, 348, 1527-1536. http://dx.doi.org/10.1056/NEJMoa020880

[28] Chang, S.R. and Chen, K.H. (2008) Age at Menarche of Three-Generation Families in Taiwan. Annals of Human Biology, 35, 394-405. http://dx.doi.org/10.1080/03014460802154777

[29] American College of Sports Medicine (2000) ACSM's Guidelines for Exercise Testing and Prescription. 6th Edition, Lippincott Williams and Wilkins, Baltimore.

[30] Peralta-Romero, J.J., Gómez-Zamudio, J.H., Estrada-Velasco, B., Karam-Araujo, R. and Cruz-López, M. (2014) Genetics of Pediatric Obesity. Revista Médica del Instituto Mexicano del Seguro Social, 52, S78-S87.

[31] Sharkey, J.R., Johnson, C.M. and Dean, W.R. (2011) Nativity Is Associated with Sugar-Sweetened Beverage and Fast-Food Meal Consumption among Mexican-Origin Women in Texas Border Colonias. Nutrition Journal, 10, 101. http://www.ncbi.nlm.nih.gov/pmc/articles/PMC3196692/pdf/1475-2891-10-101.pdf http://dx.doi.org/10.1186/1475-2891-10-101

[32] Bellini, G., Grandone, A., Torella, M., Miraglia Del Giudice, E., Nobili, B., Perrone, L., Maione, S. and Rossi, F. (2015) The Cannabinoid Receptor 2 Q63R Variant Modulates the Relationship between Childhood Obesity and Age at Menarche. PLoS ONE, 10, e0140142.

http://journals.plos.org/plosone/article?id=10.1371/journal.pone.0140142 http://dx.doi.org/10.1371/journal.pone.0140142

[33] Deng, F., Tao, F.B., Liu, D.Y., Xu, Y.Y., Hao, J.H., Sun, Y. and Su, P.Y. (2012) Effects of Growth Environments and Two Environmental Endocrine Disruptors on Children with Idiopathic Precocious Puberty. European Journal of Endocrinology, 166, 803-809. http://dx.doi.org/10.1530/EJE-11-0876 